\title{
Human issues in service design
}

\author{
Lori S. Cook $^{\mathrm{a}, *}$, David E. Bowen ${ }^{\mathrm{b}, 1}$, Richard B. Chase ${ }^{\mathrm{c}, 2}$, Sriram Dasu $^{\mathrm{c}, 3}$, \\ Doug M. Stewart ${ }^{\mathrm{d}, 4}$, David A. Tansik ${ }^{\mathrm{e}, 5}$ \\ a Department of Management, DePaul University, 1 East Jackson Boulevard, Chicago, IL 60604-2287, USA \\ ${ }^{\mathrm{b}}$ World Business Department, Thunderbird, 5249 N, 59th Avenue, Glendale, AZ 85306-6000, USA \\ ${ }^{\mathrm{c}}$ Department of Information and Operations Management, Marshall School of Business, University of Southern California, \\ Los Angeles, CA 90089-1421, USA \\ d Department of Marketing and Supply Chain Management, The Eli Broad Graduate School of Management, \\ Michigan State University, 354 N Business Complex, East Lansing, MI 48824-1122, USA \\ e College of Business and Public Administration, University of Arizona, Tucson, AZ 85721-0108, USA
}

\begin{abstract}
A heightened awareness of the fundamental behavioral science principles underlying human interactions can be translated directly into service design. Service encounter design can be approached with the same depth and rigor found in goods production. Service encounters can be designed to enhance the customer's experience during the process and their recollection of the process after it is completed. This paper summarizes the key concepts from a panel discussion at the DSI National Meeting in Orlando in November 2000. The panel brought together a number of leading academic researchers to investigate current research questions relating to the human side of the design, development and deployment of new service technologies. Human issues from the customer and service provider vantage are illustrated and challenges to researchers for exploring this perspective are presented. () 2002 Elsevier Science B.V. All rights reserved.
\end{abstract}

Keywords: Service operations; Human resource/OM interface

\section{Introduction}

The premise of this paper is that if we understand the fundamental behavioral science principles that underlie human interactions, we can indeed approach service encounter design with the same depth and

\footnotetext{
* Corresponding author. Tel.: +1-312-362-5203.

E-mail addresses: 1cook@depaul.edu (L.S. Cook),

bowend@t-bird.edu (D.E. Bowen), rchase@marshall.usc.edu (R.B.

Chase), dasu@marshall.usc.edu (S. Dasu), dmstew@msu.edu

(D.M. Stewart), dtansik@bpa.arizona.edu (D.A. Tansik).

${ }^{1}$ Tel.: +1-602-978-7011.

${ }^{2}$ Tel.: +1-213-740-0184.

${ }^{3}$ Tel.: +1-213-740-3681.

${ }^{4}$ Tel.: +1-517-353-6381.

${ }^{5}$ Tel.: +1-520-621-1710.
}

rigor found in goods production. We further contend that service encounters can be specifically engineered in such a way as to enhance the customer's experience during the process and his or her recollection of the process after it is completed. Unlike a manufacturing process, however, the engineering tools of the service encounter are concepts from psychology, sociology and their various subspecialties (e.g. cognitive psychology and behavioral decision theory). Fortunately, we have available to us a wealth of behavioral research findings which we can draw upon. For example, the behavioral literature clearly indicates the importance of event flows, end game management, being in control of one's environment and customers' emotions (Ariely and Carmon, 2000; Hsee et al., 1991; Roese and Olson, 1995; Kahneman et al., 1982; Oliver et al., 1997). 


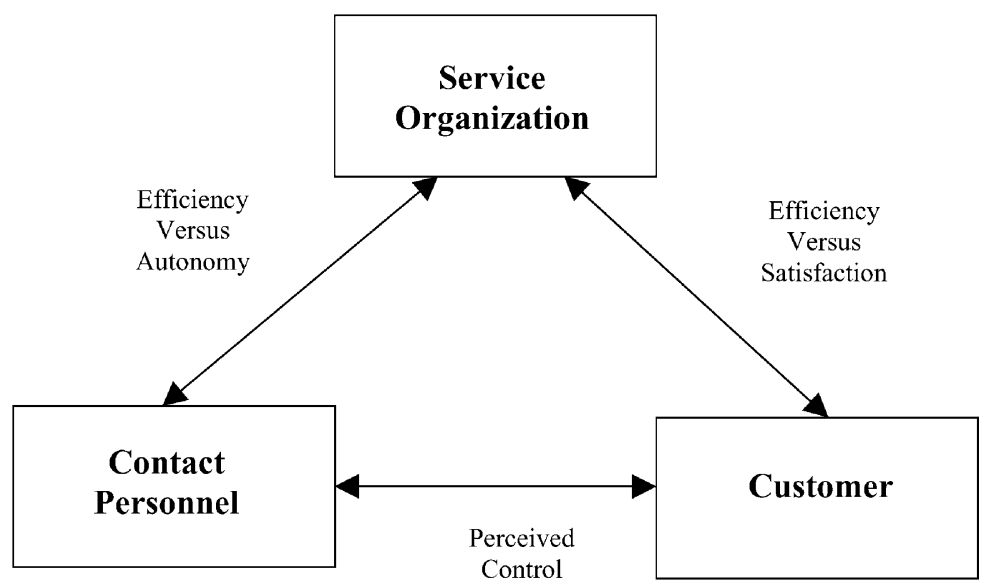

Fig. 1. The service encounter triad.

The service encounter may be viewed as a triad (Fig. 1), with the customer and the contact personnel both exercising control over the service process in an environment that is defined by the service organization (Bateson, 1985). It is mutually beneficial for the three parties to work together to create a positive service encounter. The customer, by working with the contact personnel within the framework imposed by the service organization, expects to obtain service satisfaction. The contact personnel by serving the customer in the way specified by the service organization, expects to obtain job satisfaction and customer satisfaction. The service organization must satisfy the contact personnel and the customer in a manner that is economically viable from an operations perspective.

The purpose of this paper is to challenge researchers to explore the vast array of questions relating to the human side of the service encounter design, development and deployment of new service technologies. This paper presents both issues and opportunities for research in developing human issues in the service encounter triad-the customer, the contact personnel and the service organization. Each section provides both a framework and associated research questions. The paper is developed as follows: first, we introduce the concept of applying behavioral science to service encounters. Next, the customer-focused discussion is expanded to include customer emotions, specifically, delight and outrage. We then discuss how the link between the service organization and the customer can be analyzed using customer scripting. This is followed by an examination of the contact personnel's role in the service encounter. We then discuss how mystery shopping can be used to examine the link between the service organization and the contact personnel. Finally, we conclude the paper with a discussion of the research opportunities that apply to the human side of the service encounter.

\section{Applying behavioral science to service encounters}

\subsection{Frameworks for applying behavioral science to service encounters}

A service encounter may be defined as the interaction process between the server and the served. We have selected three concepts dealing with customer behavior to explore in this discussion. These are the flow of the service experience (what's happening), the flow of time (how long it seems to take), and counterfactual reasoning in judging the encounter performance (what you thought about it later). While there are numerous other topics that pertain to behavior in services (e.g. social cognition, power and control, emotional labor) we believe that these three are essential to understanding the encounter phenomenon.

\subsubsection{Flow of the service experience}

A service encounter, no matter what its length is made up of individual experiences that flow through 
time. An overview of a Disneyland visit, e.g. consists of the experiences of waiting, going on rides, walking, eating, buying, etc. In evaluating this visit from an experiential standpoint then, we would ask the question, "does every minute of our stay in the park matter equally or do some moments or characteristics of the experience have a greater influence on our recollections?" A little retrospective analysis would probably reveal that all moments are not equally important. Typically, we create a summary assessment of our experience that not only affects our decision about whether or not to repurchase the service, but also how we approach the next encounter. What are the determinants of this summary? The answer is that our summaries it seems are not obtained by "adding up" the pleasure or pain felt during each moment of the encounter. Instead, behavioral scientists (Ariely and Carmon, 2000, Varey and Kahneman, 1992) have found that our summaries are based on three key characteristics of the experience-the trend in the pain or pleasure sequence, the high (or low) points, and the ending. We prefer a sequence of experiences that improve over time. This sequence effect is seen in other hedonic experiences such as vacations, music concerts and education. In gambling, a loss of US\$ 10 followed by a US $\$ 5$ win, is preferred to one in which we win US\$ 5 first and then lose US\$ 10 (Lowenstien and Prelec, 1993). There is also evidence that we pay attention to the rate of improvement in the sequence and prefer ones that improve faster (Hsee et al., 1991). Perhaps the most intriguing finding is the significance of the ending of an encounter. Field experiments (Kahneman et al., 1993; Redelmeier and Kahneman, 1996) suggest the specific level of pain (or pleasure) at the end of the experience can have an enormous impact on our perceptions. These findings also illustrate the relative unimportance of duration.

\subsubsection{Flow of time}

Many animals both small and large have some sense of time. Circadian cycles are evidence of our ability to keep track of long duration of time- of the order of a day. B.F. Skinner's experiments in the 1930s showed us that even rats could estimate an hour. In the jungles of Costa Rica the long-tailed hermit hummingbirds revisit flowers precisely every $10 \mathrm{~min}$ - the time required for the nectar to be replenished. You do not have to be a concert pianist to detect a missed beat. Although we all have a sense of time, how we perceive time remains an enigma. Sometimes, we can judge time accurately and on other occasions we are surprised by how much or how little time has gone by.

For over 200 years psychologists and cognitive scientists have been attempting to unravel the mysteries of how we process time. When do we pay attention to the passage of time and how do we estimate its duration? What we do know, however, is that people's view of the flow of time is often distorted by the context and content of the situation (Friedman, 1990). In this regard, one finding that has been repeatedly verified is that when we are mentally engaged in a task we do not observe the passage of time. Another is that when we are primed or prompted to pay attention to the passage of time we provide longer estimates of its duration. A third finding that also has solid experimental backing is that increasing the number of events or segments in an encounter lengthens the after the fact perceived duration. Our judgment of duration appears to be based on external changes, what we paid attention to, what we stored and what we subsequently recall.

A second question related to the passage of time is "when does duration matter in our assessments?" Research indicates that unless an activity is extremely long or extremely short relative to their expectations, people pay little attention to its duration. There are two reasons for this. First, as in our judgment of actual time, the hedonic content of the experience and how it is arranged seems to dominate our assessment. It is what you are doing, not how long you do it that sticks in people's minds. Second, for other than one-off transactions, service encounters are rarely identical in the time they take, so we have only general reference points for evaluating duration (Friedman, 1990).

\subsubsection{Counterfactual reasoning in evaluating service performance}

When something unexpectedly good happens or if something goes wrong we engage in a form of rationalization that social psychologists call "counterfactual thinking" (Roese and Olson, 1995). "I am glad Sally was at the meeting. I almost forgot to invite her. Can you imagine what would have happened if she was not there today?" or "what if I had made that phone call to the client yesterday?" We engage 
in mental simulations of events that did not occur but "might have" happened.

One of the factors that leads us to engage in counterfactual reasoning is our desire for a clearly identifiable significant cause. We are uncomfortable with the idea that a confluence of minor events could have caused an unexpected outcome. For example, if our airline flight is delayed, we perform a mental simulation to try to capture the specifics of "what if", "if only I had taken flight $\mathrm{x}$ or $\mathrm{y}$ or $\mathrm{z}$, things would have been different." Three characteristics stand out in this exercise. First, we view the likely cause as a discrete thing (x, y or z), not a continuous intertwined process whose totality determines success or failure. Second, we anchor on deviations from routines or norms as potential causes of the unexpected outcome. Third, the last event is frequently over-weighted as the cause. In summary, in the service encounter we want an explanation and we will find it. For a delayed flight the explanation must lie in the realm of things we can observe and can be relatively easily changed in our imagination (Roese and Olson, 1995). The amount of mental energy we expend in counterfactual reasoning, and the strength of emotion involved depends on how easily we can change the events leading up to the outcome.

\subsubsection{Compendium of behavioral principles}

Chase and Dasu (2001) have postulated a compendium of five behavioral principles for service encounter design and management derived from the foregoing theory and related behavioral research findings. Many of the principles listed are predicated on research findings that are themselves subject to debate among behavioral scientists.

The first principle states a service encounter should finish strong. This ties in with one of the important findings from behavioral decision theory mentioned previously: the preference for improvement. In a service encounter it is widely believed that the start and finish of a service are equally weighted in the eyes of the customer. While it is essential to achieve a base level of satisfactory performance at the beginning so that the customer remains throughout the service, a company is likely to be better off with a relatively weak start and a modest upswing on the end, than having a great start and a so-so ending.

The second principle states, we should try to eliminate the undesirable experience early in the service encounter. Behavioral research indicates that people prefer to have the bad news delivered before the good news.

The third principle states, we should segment the pleasure, combine the pain. Segmenting the encounter may be difficult but depending upon the type of encounter, it may be the best thing to do. First, events seem longer when they are segmented. Second, we have an asymmetric reaction to losses and gains (Kahneman and Tversky, 1979). These insights imply that we want to break pleasant experiences into multiple stages, and combine unpleasant ones into a single stage.

The fourth principle states, we should build commitment through choice by letting the customer control the process. Giving people control over how a process is to be conducted enhances their satisfaction with the process (Mills and Krantz, 1979).

The fifth principle states, we should pay attention to norms and rituals in the service encounter. Research on counterfactual thinking clearly points out that deviations from norms are likely to be overly blamed for failures (Roese and Olson, 1995). This is particularly true for professional services whose processes and outcomes are not clearly ascertainable by the client, and hence adherence to norms is the central basis for evaluation.

\subsection{Research questions for applying behavioral science to encounters}

There are a variety of behavioral science service encounter research activities that need to be addressed. One is simply to collect behavioral findings that seem applicable to service encounters. Behavioral scientists have identified certain biases and heuristics, not all of which are self-evident, that can be used for this purpose. A second is to classify these findings and develop frameworks that facilitate their translation from the lab to real service environments. A first cut might be classification according to when people are asked for their evaluation of alternatives-before the fact (prospectively) versus after the fact (retrospectively). Subcategories might include, respectively, sequential preferences versus sequential ratings. Finally, we need to conduct research to better understand the trade-offs that must be considered in invoking the principles in service design. For example, is the weighting of the 
importance of the final event the same prospectively as it is retrospectively? How does the passage of time play into such weightings?

So much of service is about perceptions yet, in the context of designing delivery systems, we have not fully considered how perceptions are formed. We need to focus on the underlying factors that determine how the service is perceived, and of at least equal importance, remembered.

\section{Customers' emotional responses to service encounters: delight and outrage}

Section 3.1 contributes to understanding customers' emotional responses to service and service design. First, the concept of "customer delight" and "customer outrage" as the extreme states of emotional responses to service is introduced. Next, a needs-based approach to understand customer delight is presented. This approach offers a way of conceptualizing customer evaluations of service that is different from the "met expectations" model (e.g. Zeithaml et al., 1990) that tends to dominate the customer satisfaction and service quality literature, and has also been applied to the customer delight concept (Oliver et al., 1997). Next, the proposition that the key to creating delight, and avoiding outrage, lies in satisfying, and not violating, customer needs for security, fairness, and esteem is offered. These are three basic human needs for which individuals are continually seeking gratification-even in service encounters. Finally, research questions pertaining to the customers' emotional responses of delight and outrage are presented.

\subsection{Frameworks for customers' emotional responses: delight and outrage}

The conventional framework of customer satisfaction assumes that customers have specific expectations about their interactions with an organization and by achieving those expectations the result will be customer satisfaction. Customer delight, though relatively understudied, has been explained with the "met expectations" model (Oliver et al., 1997; Zeithaml and Bitner, 1996), with the proposal that exceeding customer expectations causes customer delight. The idea is that positive disconfirmations, i.e. "pleasant surprises" activate an aroused positive, pleasant state that is experienced as the emotion of delight.

Customer outrage, though not explicitly conceptualized in the literature, resembles the customer experience of "victimization" introduced by Bell and Zemke (1987) in their work on service recovery. They mention that there are service failures that produce a response not just of "annoyance" from a modest unmet expectation, but rather a response of "ire, frustration, and/or pain" stemming from a real feeling of even betrayal.

\subsubsection{A needs-based framework}

A needs-based framework for viewing customer delight and outrage was introduced by Schneider and Bowen (1999). They thought that the met expectations model suffered some limitations in explaining these more extreme emotional responses. The met expectations model seems too cognitively oriented and rational for explaining emotions such as delight and outrage. Additionally, it would also seem that exceeded expectations would soon become habituated, and subsequently become the base of customer expectations.

An underlying premises of the needs-based framework is that customers are people first, and consumers second. Additionally, people are driven to satisfy some core needs in life at a level more fundamental and compelling than meeting their expectations as consumers. The core needs we consider are as follows:

Security: The need to feel free from physical and economic harm.

Fairness: The need to believe that just treatment is deserved.

Esteem: The need to protect, even, enhance one's self-concept.

The needs for security and esteem are derived from the need hierarchy theories of Maslow (1943) and Alderfer (1972). The need for fairness has its origins as far back as Aristotle, who said that we all want to believe that we live in a just world. Refer to Lerner (1980) for a more complete discussion. Needs exist at a deeper, more subconscious, more diffuse level than do expectations. Schneider and Bowen (1999) proposed for security and fairness, violation causes outrage. Respecting these two needs is more likely to lead to satisfaction than to delight. For esteem, violation can cause outrage. Enhancing customer's esteem is likely to create delight. 
3.1.1.1. Security. Security is the most basic of all human needs. As a consequence, customers cannot be satisfied with the core service, itself, until they first feel secure and safe. As an example of effective management of this need, Disney endlessly scrubs their theme parks not just to produce an attractive servicescape, but also because they have determined that "unclean equals unsafe" in customers' minds.

The appearance of instability can also threaten the need for security. Corporate restructuring, mergers and acquisitions can pose such a threat. For example, when Janus Capital publicly spoke out against its parent company KCSI to avoid being included in a new spin-off company, "it was not the sort of comment that gives investors confidence in the stability of the firm managing their hard earned savings" (Fortune, 22 January 2001, p. 80). Also, security concerns have limited customer use of e-tailing alternatives.

3.1.1.2. Fairness. The primary issue of fairness is for the firm to honor, rather than violate, the customer's psychological contract with the firm. This is an unwritten, implicit agreement in the customer's mind whose basic terms are that if I, the customer, have abided by the pricing and consumption rules of the game, then the firm should be expected to deliver fully the benefits promised in its service offering. Scott Cook, founder of Intuit, demonstrates an understanding of fair execution of the psychological contract when he states that, "we, Intuit, have their (the customer's) money; we owe them success."

Customers expect fair treatment in both initial service delivery and, particularly, in cases of recovery from a service failure (Bowen et al., 1999). What does fair treatment entail from the customers' viewpoint? This question has been addressed by academics (Bowen et al., 1999; Clemmer and Schneider, 1996; Bettencourt and Brown, 1997; Seiders and Berry, 1998) by borrowing from the organizational justice literature (e.g. Greenberg, 1987). Customers seek three types of justice/fairness: distributive (the service outcomes themselves); procedural (the means, practices, and policies that lead to the outcomes); and interactional (the quality of communication about outcomes between the parties involved).

3.1.1.3. Esteem. Violating the need for esteem can produce outrage, as is also true of the needs for security and fairness. Additionally, though, enhancement of customer esteem by the service provider can be a real source of customer delight.

Service providers often violate the need for esteem when, as examples, they: deny claims of dissatisfaction; forget the names of frequent or high-revenue customers; create situations in which customers are left doubting their own competence; and engage in discriminatory service.

Means by which the need for esteem can be enhanced include: treat the customer as an important individual, not just as another member of a large class of individuals. For example, doctors could listen more fully to a patient describe their case history before interrupting to pronounce that the patient is just like others he has had to listen to, and does not need to hear more from this one. Another possibility is to enhance customer feelings of control. This can range from better signage in facilities to self-management of one's IV drip in the hospital. In both cases, the individual is able to experience a sense of mastery over their situation. This feeling of being in control, and how that enhances one's view of self, can be enhanced by sharing information with customers (airlines about delays; doctors about diagnoses and prognoses). Finally, it also appears that providing customers choices in service delivery alternatives enhances their feelings of control and, as a consequence, esteem (Langeard et al., 1981; White, 1959).

\subsection{Research questions for customers' emotional responses: delight and outrage}

The research questions presented focus almost exclusively on conceptualization and largely ignore issues of methods. Issues of appropriate methodology for testing needs based theories are exceedingly complex, largely due to the subconscious nature of the phenomenon (see Miner, 1980 for a discussion of this relative to Maslow's and Alderefer's need theories).

One area would be to consider whether there are other needs that influence the customer's evaluation of service designs. For example, is there a need for fun, or joy, that humans share? Southwest Airlines appears to believe so or to believe that there is at least a certain market segment that does. Another possibility involves aesthetics; the need to experience beauty. Dean et al. (1997) have written about how even organizations can 
be experienced as beautiful. Beauty brings to mind delight; ugliness connotes outrage.

A critical incident technique (CIT) (Flanagan, 1954) could be used to catalogue service encounter incidents that customers experience as either delight or outrage. These CITs could possibly be collected using the mystery shopping methodology described in Section 6. In turn, researchers could attempt to sort the CITs into three need categories: security, fairness and esteem.

More research needs to be done on the role of customer emotions in the evaluation of service. Several articles in recent years have examined the role of emotions such as joy, anger, and guilt in service satisfaction (Dube and Menon, 2000; Lijander and Strandvik, 1997; Price et al., 1995). Emotions have been viewed both as a post-consumption response (true of most of the limited work on delight), and as the emotional state the customer brings to the service encounter. On the latter, is it easier to delight an already joyful customer, or might the opposite be true?

The emotions in service studied by Dube and Menon (2000) demonstrated how in-process experiences of different emotions at different stages of extended service transactions affect post-purchase satisfaction. Dube and Menon suggest that the precise mechanisms by which trends in consumption emotions form over time and relate to post purchase satisfaction are still largely uninvestigated. They draw upon the previously noted work by Khaneman and his colleagues (e.g. Varey and Kahneman, 1992) that indicate the value of an experience is largely shaped by peak and final moments of the episode. As to the three needs, do critical incidents that affect the gratification of needs for security, fairness, and esteem matter most at the beginning, middle, or end of the service experience? Does it vary depending on whether the incident involves gratification versus violation? Do the dynamics vary at all by which of the needs is involved, i.e. is there content (type of need) by process (timing of events that gratify or violate a need) interaction?

Given the interest in relationship marketing and management - that is, attracting, developing and retaining customers-it could be fruitful to explore how to build relationships upon gratification of these three needs. One avenue would be to connect this needs-based perspective to work on "relational benefits"- benefits customers receive in a relationship with a service firm that are above and beyond the core service performance (e.g. Gwinner et al., 1998). For example, these researchers described "confidence", "social", and "special treatment" benefits in terms that could potentially be associated with security, esteem and fairness needs, respectively. They also tried to establish which relational benefits matter most to customers across different types of services. This is an interesting area to explore for the three needs, as well, relative to which needs are most sensitive for different types of service.

Attempting to understand human issues in service design naturally takes one into issues of emotions such as delight and outrage, as well as the domain of relationship marketing and management. A needs-based approach provides a potentially useful path to travel into those areas. Indeed, not just the customer, but the employee possesses these three needs, as well. The degree to which a service business can manage the human needs of both parties will strongly influence the satisfaction of each.

\section{Linking the service organization and the customer: customer scripting}

In the service encounter triad, the encounter dominated by the customer is controlled by the extremes of standardized service or customized service. Customers interact with services according to some pre-existing paradigm of how the service ought to act. These paradigms are referred to as scripts. Scripts are important because the amount of similarity between the scripts used by different customers can indicate where standardization is value added, and where customization of the service would be more appropriate. Moreover, conflict between the service system design, and the customer's chosen script is a major source of service failure (Stewart and Chase, 1999). Such failures can result from one of two major sources. First, the customer could choose an inappropriate script for their service encounter, in essence, engaging in the encounter under a different set of rules and expectations. Second, the service design could deviate from the existing script in some important way, in essence deviating from the established rules of behavior. 


\subsection{Frameworks for customer scripting}

Scripting is not new to services. It has been applied extensively to service employees as, primarily a means of establishing standardization and decreasing mental workload (Tansik and Smith, 1991). This work is grounded in a substantial body of literature from psychology and cognitive science.

In the context of scripting service providers, the script is a behavior trained into the worker as the desired means of conducting an encounter. The service design challenge in scripting customers is that there is little opportunity to train most customers extensively, and scripts must be selected instead from those that exist at-large.

Three major issues must be addressed in designing for customer scripting. First, we must select an appropriate and desirable script from those we expect the customer to know. If a specific script is not chosen, then we cannot plan for one in the service design. In essence we leave the choice of script in the hands of each customer, and hope that individual customers select similar scripts, and that those chosen are sufficiently close to the actual service design. Second, we must ensure that the service system is consistent with this script on the important dimensions. Finally, we must elicit this desired script during the service encounter. If there is disagreement between the script chosen by the customer and the service process, the customer will follow the script chosen and attribute any deviations as faults of the service system. Failure to explicitly address customer scripting will often lead to a service design that is prone to service failures.

We must also be concerned with the variability found within a customer script. First, is the variability between the same basic script that is followed by different customers. These are areas where consistent behavior cannot be expected between customers, even when the desired script is successfully evoked. This variation must be allowed for in the service design. The second form of variability is the variability that an individual customer will accept within a chosen script. These areas of variability are places that the service offering can be easily tailored to suit the needs of the customer without disrupting the active script, and are likely to be places where such customization is expected.

\subsection{Research questions for customer scripting}

A crucial component of the service encounter is examining the control link between the service organization and the customer. Customer scripting offers a framework to address many research questions with respect to this relationship. The first question is what are the commonly available customer scripts? We know that the development of scripts is a natural by-product of an individual's ongoing efforts to minimize cognitive effort. We also know that there are many standard scripts that individuals have in common, and that are used in a variety of service environments (e.g. the sit down restaurant scripts). What we need to understand is how many such common scripts are available, and how many service encounters that appear different on the surface are actually serviced by the same basic scripts. Some attempt to catalog the commonly encountered and used scripts, and how such scripts are hierarchically organized, is needed.

Another issue to address is how to match the service design to the chosen script. The most obvious aspect of such a match will be to ensure that those process steps where the customer is involved proceed according to the script. One less obvious aspect is the need to match the outward manifestations of back office processes to the customers' perceptions about how they progress, so that the expectations for the output of these processes remain reasonable. We are also likely to find that the desired script will also contain specific expectations about the treatment to be accorded the customer within the encounter, as well as expectations surrounding the tangible aspects. Bitner (1992) has addressed the psychological impact of the service environment on the customer, and this work may be a good starting place to investigate these issues further.

The next issue to address is how to best evoke a desired script from the customer. There are many possible avenues that can be pursued. We know that certain cues in the environment can be used to prompt the desired script. We must understand how to identify those cues that are important for selecting the desired script, highlight the appearance of those cues, while removing those that are extraneous from the environment. Scripts may also be summoned more easily from other closely associated scripts. It may 
be possible to prompt a script more consistently if the customer can be first engaged in some preliminary script that primes him for the later script. For example, to prompt a customer to behave as if in a doctor's consultation, it may help to first run the customer through a script appropriate for a nurse triage.

Given the general prevalence of script use by customers, another related issue of interest is how to handle and control undesirable scripts. For example, a customer may evoke (and may even become entrapped within) an "irate customer" script in response to a service failure perceived as a personal affront. Or, perhaps a customer with a different cultural background may use a script that is not appropriate in the current service encounter. This could be using a "mob the counter to get service script" when an orderly queue is called for, or going through a clothes display as if it were a rummage bin, rather than a folded table display. It should be possible to preempt an undesirable script before it takes control by introducing triggers into the environment that direct behavior down more desirable paths. Or, once such a script has taken hold, certain triggers may be able to break the script or at least redirect it. Specialists in service recovery take such actions regularly, based on their observations of what works and what does not. The introduction of scripts to the service recovery function would provide a theoretical basis to better guide such actions.

Finally, we should consider how customer scripting-basically a technique to standardize behavior across customers - fits with the trend towards more customized services. Scripting can be used to reduce the anxiety associated with the unfamiliar, as well as decrease the required cognitive effort required by the customer, while still allowing customized service in those parts of the encounter where it really adds value to the customer. This is not surprising when we consider the role that ceremony (explicit social scripts) plays during life's stressful events. Funerals, weddings, graduations, award ceremonies, and even large social parties rely extensively on ceremony. The social script allows the participants to focus on the eulogies, vows, toasts and speeches that make such events special, without having the strain of thinking about every little detail.

\section{Linking the contact personnel and the customer: employee role}

The service employees represent the organization in the customers' eyes and in many instances they are the service. In the service encounter triad, the importance of flexibility in meeting the customers' needs has resulted in many service organizations examining the role of their contact personnel. Many organizations will immediately seek the customer viewpoint for service quality assessment. Selecting the appropriate tools and collecting the data can be a time consuming and costly task. Front-line service employees are in an optimal position to report on the degree to which strategic initiatives are being accomplished. The front-line service employees represent the critical link from the service organization to the customer. They are responsible for both understanding customer needs and for interpreting customer requirements in real-time. Properly conducted, service quality culture and strategic consensus assessment has the potential of informing a service organization of its current position and potential areas for service system improvement.

\subsection{Frameworks for the employee role}

In an oft-cited study, Heskett et al. (1994) introduced the concept of the service-profit chain (Fig. 2). They examined the critical interaction of the front-line service employee and the customer and demonstrated that profitability, and customer loyalty is closely related to employee productivity and motivation. The fundamental propositions of the service-profit chain are as follows: customer loyalty drives profitability, customer satisfaction drives customer loyalty, external service value drives customer satisfaction, employee productivity drives external service value, employee loyalty drives productivity, employee satisfaction drives loyalty and internal service quality drives employee satisfaction. They propose that organizations that understand the service profit chain develop and maintain a corporate culture centered on service to both their customers and employees.

Employees' values and beliefs (part of culture) influence their interpretations of organizational policies, practices and procedures (climate). Schneider et al. (1996) propose that culture can be changed through a focus on climate. They assert that sustainable 


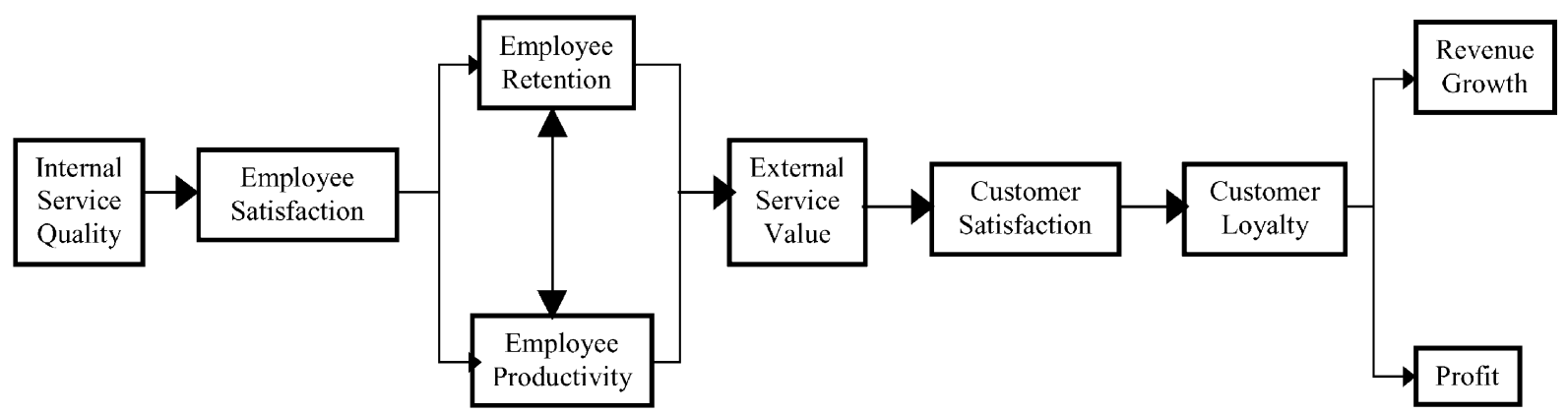

Fig. 2. The service profit chain.

organizational change is most likely to occur when both the climate and the culture change. Effective organization change occurs when new climates and cultures are created and maintained. No single climate or culture is best for achieving sustained change.

Schneider and Bowen (1993) have shown that both a climate for service and a climate for employees' well being are highly correlated with overall customer perceptions of service quality. They conclude that both the service climate and human resource management experiences that employees have within their organization are reflected in how customers experience the service. Bowen and Lawler (1992) contend that motivated, empowered employees who have a clear vision of the importance of service quality to the firm will provide superior service. The result of superior service should be an increase in customer satisfaction.

Hays and Hill $(1999,2001)$ investigated the effects of employee motivation and vision and organizational learning on customer perceived service quality in a service organization. The results of their research indicated that employee motivation, vision and organizational learning positively affect customer perceived service quality. They also found that employee motivation and vision mediate the relationship between organizational learning and customer perceived service quality.

Researchers and practitioners have initiated the use of employee surveys to assess more than employee morale, attitudes toward the company, and job satisfaction (Higgs and Ashworth, 1996). These new surveys have been designed to focus on strategic imperatives of the corporation. Schneider and Bowen (1985) demonstrated that employee descriptions of the policies and practices of their organization with regard to creating a service quality climate were significantly related to customer perceptions of the service quality they received.

Schneider et al. (1996) describe the development, implementation, validation and use of a strategically focused employee attitude survey to assess a variety of issues related to a quality management initiatives. The survey focused on the initiative rather than on employees' personal feelings or satisfaction. The validity of employee reports is demonstrated by establishing the relationship between those reports and customer satisfaction in dealing with the organization.

Bowen et al. (1999) suggests that in service firms, if employees are treated fairly, they will treat their customers more fairly. Research conducted in a variety of service settings has shown that employee satisfaction correlates significantly with customer satisfaction. Fairness issues are an expression of different types of justice: distributive, procedural and interactional. They offer four basic general managerial guidelines in which to enact the more specific justice principles. First, examine the "psychological contract" with its employees-and customers. Second, train managers and customer contact employees in how to honor the "justice principles." Third, balance flexibility and consistency in the design and implementation of procedures. Finally, share justice-relevant information with employees and customers.

The perception of service quality results from a comparison of customer expectations with actual service performance. Service employees impact the perception primarily due to their influence on all five dimensions of service quality: reliability, responsiveness, assurance, empathy and tangibles (Parasuraman et al., 1985, 1988, 1991a,b). Reliability corresponds 
directly to the service outcome and is often cited as the most important dimension for assessing service. The service process dimensions are responsiveness, assurance, empathy and tangibles. Reliability is essential for meeting expectations but the process dimensions are more important for exceeding expectations. Reliability is the fundamental requirement to compete in the marketplace but for the service organization to gain competitive advantage their service employees must leverage the process dimensions.

\subsection{Research questions for the employee role}

There are a variety of research activities that need to be conducted to further examine the relationship between the service employee and the service encounter. For organizations to succeed, it is essential for service employees to understand the interrelationships between internal quality systems and the impact on service quality provided to the customers. Employees must understand that superior service quality can lead to higher levels of operational performance. The organization must closely monitor and conform to the needs and preferences of their customers while maintaining desirable levels of service quality. Top management is responsible for climate and culture, and thus for the degree to which it is implemented and sustained. It is essential to build a "quality" culture and climate within the realm of the organization.

The service employee is the foundation of the service profit chain. The first link in the service profit chain is the relationship between employee satisfaction and internal service quality. The internal service quality consists of workplace design, job design, employee selection and development, employee rewards and tools for serving customers. It is measured by the feelings that employees have towards their jobs, colleagues and the organization. Ultimately, the service employee is the driver of external service value to the customer. Further research needs to be conducted to empirically assess employee involvement in the fundamental propositions of the service-profit chain. How can we strategically utilize our employees to assess service quality? Can an organization use their employees to assess the entire chain? Is there value in using employees to assess the customers' perceptions?

Management must have a candid view of their success in translating the service quality mission to all levels of employees within the organization. There is a host of issues that need to be investigated. How can we gauge the service quality climate and culture of an organization? After conducting an assessment can we determine specific actionable items having significant impact on customer satisfaction, employee satisfaction and company culture? The service impact of climate and cultural issues also needs to be examined. Are employees familiar with the organizations' emphasis on quality? Does management's actions demonstrate to the employees that service quality is important to the organization? Do employees understand the service quality measurements used in their organization? Do employees feel that their achievement of service quality standards impacts their performance evaluation? Have employees been involved with quality related improvement teams? Finally, what is the strategic implication of having a service quality culture and climate?

The high correlation of service quality perceptions that are shared by contact personnel and customers leads to further research of management's contribution to create a customers service orientation. Employee related issues define the operating and the service delivery system. How can we use our employees to leverage this key link? Can we assess the relationship between customer satisfaction and employee satisfaction by performing an initial assessment of service quality (perceptions and expectations) though the employee perspective.

Parasuraman et al. (1991) introduce the zone of tolerance concept. The tolerance zone is formed by assessing the minimal level of service acceptable to the customers (adequate service) and the level the customer believes the service should be and can be (desired service). Can we use our employees to help determine the zone of tolerance for service dimensions? How does the zone expand and contract for varying degrees of customer contact? How does employee satisfaction and the service systems in place effect the tolerance zone?

Finally, further research needs to be conducted to explore the linkages between employee quality climate and culture, strategic operational consensus, and business performance. Ultimately, we need to identify the relationship between quality systems, service quality and organizational performance. There are countless employee issues that must be considered in service research. The definitive question is how can we 
strategically utilize our employees to assess service system design quality to gain a competitive advantage?

\section{Linking the service organization and the contact personnel: mystery shopping}

In the service encounter triad, an encounter dominated by the service organization results in a situation where the contact personnel is expected to deliver standardized service through defined structured operating procedures. A mystery shopper is a surrogate guest/customer who, unbeknownst to the service provider, evaluates the service against an 'ideal' and then objectively reports out on their experience. Mystery shopping is thus limited to those events that can be viewed or experienced by customers. Based upon the type of feedback desired by the organization, the mystery shopper will have varying degrees of knowledge about the product they are evaluating. The typical mystery shopping experience requires the shopper to go through some training about the organization and its service product, and then visit the organization disguised as a customer and purchase or pretend to purchase the service. The shopper will be looking for a series of service expectations that the organization has (hopefully) trained and/or instructed the service provider to deliver.

\subsection{Frameworks for mystery shopping}

Several types of mystery shopping events typically take place, not all focusing on just customer or guest service. The most common mystery shopper activity and the primary focus in this section is the 'service shop'. The 'service shop' involves an on-site objective evaluation covering such issues as assessing the general appearance of the location; determining whether or not employees were helpful, friendly and courteous; seeing if company procedures were followed in completing the transaction; and deciding if the service was performed appropriately and in a timely fashion.

Realizing that management and customers might differ concerning what constitutes poor, good, or excellent, service, Parasuraman et al. (1985) noted five 'gaps' that can occur when there is a mispecification or mismanagement (between managers and customers) of the definition of and delivery of excellent service. Gap one is the discrepancy between customer expectations and management perceptions of those expectations. For example, not knowing what the customer wants. Gap two is the discrepancy between management's perceptions of what constitutes a desired target level of quality and the necessary tasks to deliver that product. For example, not knowing how to produce and deliver what management thinks is desired by customers. Gap three is a discrepancy between service quality standards that are publicly articulated by management and those that are actually utilized. For example, the worker not producing what management desires. Gap four is the discrepancy between what the organization actually produces and what it tells customers it is producing. For example, not delivering what you say you will, or want, to deliver. Finally, gap five is the discrepancy between what a customer expects and what her or she perceives is actually delivered. For example, the customer not getting what was expected.

Mystery shopping specifically addresses issues in gap three. The other gaps should not be ignored, but rather addressed by management as part of its overall service strategy. Well-trained employees equipped with the right tools and resources should be capable of delivering the service that management intends. Mystery shoppers, then, can help assess how well the organization's employees are performing their jobs by comparing their actual experiences with management's intentions.

There are several potential pitfalls that can result in a less-than-optimal experience in a mystery shopping program. First, a crucial pitfall is measuring just those things that can be easily measured, and not what is really important to the customer or the operation. Thus, determining the criteria the mystery shopper will measure is critical. These criteria must be customer-relevant and be drawn from management's attention to gap one, understanding what the customer wants. One of the most important elements in a well-managed service organization is the relationship between the guests expectations and the design of the 'system' within the organization in order to meet those expectations. Ford and Heaton (1999) refer to this concept as guestology; treating customers 
like guests and managing the organization from the guest's point of view. An essential part of guestology is measuring employees' performance of critical success factors that tie in with service guarantees that the organization provides. This is also at the heart of any effective performance management tool, including mystery shopping. For example, one mystery shopper program measured whether the employee being shopped was wearing a nametag. Although in this corporate culture the wearing of a nametag may be deemed important, it probably has little effect on the customer's overall experience. Hayes (1992) discusses several means of conducting a strict item analysis process to ensure that the questions measured on a service evaluation tie directly back to what is important to the customer and the business. In the end, what is it that the customer sees, feels, hears, smells and tastes? Those sensory inputs to the customer are key elements of what mystery shopping should focus on.

Mystery shoppers should not be used to measure what something or someone else can effectively measure. The intent of the mystery shopper should not be to replace management's presence and oversight. An illustration of this would be asking mystery shoppers to measure an item for which there is already a 'better', more scientific, measurement tool. For example, a fast food establishment asked its shoppers to rate the 'brix', or carbonation level, of the soda being served in the establishment. While this is indeed measurable by the mystery shopper, a more accurate measurement exists in the form of a 'brix kit'-a device used to measure the optimal levels of syrup and carbon dioxide in a soda. The beverage industry has understandably made a science out of balancing their sodas for the perfect drink and they have created a very reliable measure to help them insure that they produce the desired product. Again using the nametag example earlier, an organization does not need a mystery shopper to tell management when their employees aren't wearing nametags - a manager or other employee can observe that. The point is that mystery shoppers provide a 'surrogate customer' point of view and should only be used in situations where the customer point of view is needed.

Another pitfall is the ineffective use of mystery shopper data. Not using these data effectively seems to fall into three categories: not using it at all, using it as a 'hammer' with which to punish employees, or not using it to make operational or process improvements. When a surrogate customer provides feedback, this presents a learning opportunity for the organization. The insight into the customer experience can provide important clues into customer requirements. The data should be used to make improvements in the system's operation for the benefit of all customers and employees. Many service organization problems are related to ineffective processes, not poorly performing employees. And, mystery shopping may be able to identify where a process or operational oriented problem is occurring, especially if it is repeatedly reported. Finally, when the mystery shopping data indicate employee successes, these need to be acknowledged and celebrated.

\subsection{Research areas for mystery shopping}

There are three primary areas where research is called for regarding mystery shopping: employees, management and customers. First is the impact of mystery shopping on the employee, specifically morale and productivity. Does getting mystery shopped affect employee morale? And, if so, what are the implications for such factors as job satisfaction and turnover? The concept of the service-profit chain (Heskett et al., 1994) emphasizes the critical interaction of the employee driven external service value and customer satisfaction. What is the impact of mystery shopping on the service profit chain? How does mystery shopping affect job design and employee training? Does mystery-shopping lead to employees having a better understanding of their job requirements?

Second is the impact of mystery shopping on management. Does mystery shopping cause or allow managers to engage in different actions? Do they supervise as closely (as those in non-mystery shopped organizations)? Mystery shopping is a tool to be used to obtain a customer's eye view of the organization. It is limited to areas normally exposed to customers and is intended to facilitate an organization's evaluation of its performance. A mystery shopping program should not replace 'normal' management oversight of an organization. It may change the nature of this oversight (e.g. from close monitoring of employees to more 'coaching'), however it should not be a management replacement. 
Third is the impact mystery shopping can have on 'regular' customers. Do organizations that use mystery shopping have higher levels of customer satisfaction? If so, does this translate into customer loyalty and profitability?

Being mystery shopped should be considered a routine part of the job, something that is known and expected. Still, assuring that employees are aware of the program in advance seems a commonsense, ethical approach. It is not only the high customer contact employee that can get mystery shopped. Audit Shops are performed to evaluate whether the organization is in compliance with some set of predetermined criteria, e.g. compliance with its franchise or company 'rules'. Via an audit shop the shopper can observe factors under management control such as hours, décor, products offered, and the like. Thus, a 'home office' can obtain realistic reports and maintain some control of a geographically dispersed system's operation without having to institute what could be costly real-time measures.

\section{Conclusions}

The objective of this paper is to explore the vast array of human issues involved in service system design. Service system design can be approached with the same depth and rigor found in goods production. The resulting impact is a heightened awareness that fundamental behavioral science principles underlying human interactions can be translated directly into service design.

Perceptions are the defining element of the service encounter. However, in the context of designing service systems, we often have not fully considered how these perceptions are formed. It is essential to focus on the underlying factors that determine how the service is perceived, and of at least equal importance, remembered. This facilitates the service organization to take control and better manage the customer's encounter.

When attempting to understand human issues in service design we must consider the range of customer emotions, in particular delight and outrage. We can manage the customers experience while reducing the stress and mental workload on the customer, shaping expectations for the encounter, gaining efficiency on those parts of the service that are expected to be familiar, and devoting individual tailored attention to those parts of the service expected to be unique and add extra value. Customer scripting can be an important tool for managing the encounter experience and reducing service failures. Through the script, we gain a better understanding of the existing available scripts, how they can be elicited, and how they connect with our service designs.

The importance of the contact personnel in successful service organizations cannot be underestimated. Ultimately, employees define an organization. Organizational change cannot take place without employees changing. The success of any market- focused organization also depends on employees' acceptance of quality climate and culture. The service organization can use mystery shopping to evaluate and assess the service encounter between the customer and the contact personnel.

Further research is needed to investigate the relationships in the service encounter triad with the customer and the contact personnel both exercising control over the service process in an environment that is defined by the service organization. It is imperative that all three parties work together to create a rewarding service encounter. The compendium of behavioral principals proposed by Chase and Dasu (2001) offer an initial starting point to examine the relationship between behavioral research findings and service encounter design and management. Finally, research needs to be conducted to explore each component and link in the service encounter triad. The ability to establish and measure the linkages throughout the triad has important implications for service delivery system design and management. The degree of fit between an organization's competitive priorities and its key decisions regarding service system design provides the key to developing the full potential of service operations as a competitive advantage.

\section{References}

Alderfer, C.P., 1972. Existence, Relatedness, and Growth: Human Needs in Organizational Settings. Free Press, New York. Ariely, D., Carmon, Z., 2000. Gestalt characteristics of experiences: the defining features of summarized events. Journal of Behavioral Decision Making 13, 191-201. 
Bateson, J., 1985. Perceived control and the service encounters. In: Czepiel, J.A., Solomon, M.R., Surprenant, C.F. (Eds.), The Service Encounter. Lexington Books, Lexington, MA.

Bell, C.R., Zemke, R.E., 1987. Service breakdown: the road to recovery. Management Review (October), 32-35.

Bettencourt, L.E., Brown, S.W., 1997. Contact employees: relationships among workplace fairness, job satisfaction, and prosocial behaviors. Journal of Retailing (Spring), 39-62.

Bitner, M., 1992. Servicescapes: the impact of physical surroundings on customers and employees. Journal of Marketing $56,57-71$.

Bowen, D.E., Lawler, E.E., 1992. The empowerment of service workers: what, why, how, and when. Sloan Management Review 33 (3), 31-39.

Bowen, D.E., Gilliland, S., Folger, R., 1999. HRM and service fairness: how being fair with employees spills over to customers. Organizational Dynamics 27 (3), 7-23.

Chase, R.B., Dasu, S., 2001. Want to perfect your company's service? Use behavioral science. Harvard Business Review (June), 79-84.

Clemmer, E.C., Schneider, B., 1996. Fair service. In: Swartz, T.A., Bowen, D.E., Brown, S.W. (Eds.), Advances in Services Marketing and Management, Vol. 5. JAI Press, Greenwich, CO.

Dean, J.W., Ramirez, R., Ottensmeyer, E., 1997. An aesthetic perspective on organizations. In: Cooper, C., Jackson, S. (Eds.), Handbook of Organizational Behavior. Wiley, New York.

Dube, L., Menon, K., 2000. Multiple roles of consumption emotions in post-purchase satisfaction with extended service transactions. International Journal of Service Industry Management 11 (3), 287-304.

Flanagan, J.C., 1954. The critical incident technique. Psychological Bulletin 51, 327-358.

Ford, R.C., Heaton, C.P., 1999. Managing the guest experience in hospitality. Delmar Thomson Learning.

Friedman, W.J., 1990. About Time: Inventing the Fourth Dimension. MIT Press, Cambridge, MA.

Greenberg, J., 1987. A taxonomy of organizational justice theories. Academy of Management Review 12, 9-21.

Gwinner, K., Gremler, D.D., Bitner, M.J., 1998. Relational benefits in service industries: the customer's perspective. Journal of the Academy of Marketing Science 26 (2).

Hayes, B.E., 1992. Measuring customer satisfaction: development and use of questionnaires. ASQC Quality Press.

Hays, J.M., Hill, A.V., 1999. Gaining competitive service value through performance motivation. Journal of Strategic Performance Measurement 3 (5), 36-40.

Hays, J.M., Hill, A.V., 2001. A preliminary investigation of the relationships between employee motivation and vision, service learning, and perceived service quality. Journal of Operations Management 3 (19), 335-349.

Heskett, J.L., Jones, T.O., Loveman, G.W., Sasser, W.E., Jr., 1994. Putting the service-profit chain to work. Harvard Business Review. March-April, 164-174.

Higgs A.C., Ashworth, S.D., 1996. Organizational Surveys: Tools for Assessment and Research. Jossey-Bass, San Francisco, pp. 19-40.
Hsee, C.K., Abelson, R.P., Salovey, R.P., 1991. The relative weighting of position and velocity in satisfaction. Psychological Science 2, 263-266.

Kahneman, D., Tversky, A., 1979. Prospect theory: an analysis of decisions under risk. Econometrica 47, 263-291.

Kahneman, D., Slovic, P., Tversky, A., 1982. Judgment Under Uncertainty: Heuristics and Biases. Cambridge University Press, New York.

Kahneman, D., Fredrickson, B.L., Schreiber, C.A., Redelmeier, D.A., 1993. When more pain is preferred to less: adding a better end. Psychological Science 4, 401-405.

Langeard, E., Bateson, J.E.G., Lovelock, C.L., Eiglier, P., 1981. Service Marketing: New Insights from Consumers and Managers. Marketing Science Institute, Cambridge, MA.

Lerner, M.J., 1980. The Belief in a Just World. Plenum Press, New York.

Lijander, V., Strandvik, T., 1997. Emotions in service satisfaction. International Journal of Service Industry Management 8 (2), 148-169.

Lowenstien, G., Prelec, D., 1993. Preferences for sequence of outcomes. Psychological Review 100, 91-108.

Maslow, A.H., 1943. A theory of human motivation. Psychological Review 50, 370-396.

Mills, R.T., Krantz, D.S., 1979. Information, choice, and reactions to stress: a field experiment in a blood bank with laboratory analog. Journal of Personality and Social Psychology 37 (4), 608-620.

Miner, J.B., 1980. Theories of Organizational Behavior. Dryden Press, Hinsdale, IL.

Oliver, R.L., Rust, R.T., Varki, S., 1997. Customer delight: foundations, findings, and managerial insight. Journal of Retailing 73 (3), 311-336.

Parasuraman, A., Zeithaml, V.A., Berry, L.L., 1985. A conceptual model of service quality and its implications for future research. Journal of Marketing 49, 41-50.

Parasuraman, A., Zeithaml, V.A., Berry, L.L., 1988. SERVQUAL: a multiple item scale for measuring consumer perceptions of service quality. Journal of Retailing 64 (1), 12-40.

Parasuraman, A., Berry, L.L., Zeithaml, V.A., 1991. Refinement and reassessment of the SERVQUAL scale. Journal of Retailing 67 (4), 420-450.

Parasuraman, A., Berry, L.L., Zeithaml, V.A., 1991. Understanding customer expectations of service. Sloan Management Review, 39-48.

Price, L.L., Arnould, E.J., Deibler, S.L., 1995. Service provider influence on consumers' emotional response to service encounters. International Journal of Service Industry Management 6 (3), 34-63.

Redelmeier, D.A., Kahneman, D., 1996. Patient memories of painful medical treatments-real time and retrospective evaluation of two minimally invasive procedures. Pain 66, 3-8.

Roese, J.N., Olson, J.M., 1995. Counterfactual thinking: a critical overview, in: Roese, J.N., Olson, J.M. (Eds.), What Might Have Been: The Social Psychology of Counterfactual Thinking. Lawrence Erlabuam Associates, NJ, pp. 1-56.

Schneider, B., Bowen, D.E., 1985. Employee and customer perceptions of service in banks: replication and extension. Journal of Applied Psychology 70, 423-433. 
Schneider, B., Bowen, D.E., 1993. The service organization: human resources management is crucial. Organizational Dynamics 21 (4) (Spring), 39-52.

Schneider, B., Bowen, D.E., 1999. Understanding customer delight and outrage. Sloan Management Review 41 (1), 35-45.

Schneider, B., Ashworth, S., Higgs, A.C., Carr, L., 1996. Design, validity, and use of strategically focused employee attitude surveys. Personnel Psychology 49 (3), 695-705.

Schneider, B., Brief, A., Guzzo, R., 1996. Creating a climate and culture for sustainable organizational change. Organizational Dynamics 24 (4), 6-19.

Seiders, K., Berry, L.L., 1998. Service fairness: what it is and why it matters. Academy of Management Executive 12, 8-20.

Stewart, D.M., Chase, R.B., 1999. The impact of human error on delivering service quality. Production and Operations Management Journal 8 (3), 240-263.

Tansik, D.A., Smith, W.L., 1991. Dimensions of job scripting in service organizations. International Journal of Service Industry Management 2 (1), 35-49.

Varey, C.A., Kahneman, D., 1992. Experiences extended across time: evaluation of moments and episodes. Journal of Behavioral Decision Making 5, 169-185.

White, R.W., 1959. Motivation reconsidered: the concept of competence. Psychological Review 66, 297-333.

Zeithaml, A., Bitner, M., 1996. Services Marketing. McGraw-Hill, New York.

Zeithaml, A., Parasuraman, A., Berry, L.L., 1990. Delivering Quality Service. Free Press, New York.

David E. Bowen received his $\mathrm{PhD}$ from Michigan State University (1983) and is presently Dean of Faculty and Professor of Management at Thunderbird, The American Graduate School of International Management. $\mathrm{He}$ is the guest Co-Editor of the Academy of Management Executive forthcoming special issue, "Services: Enhancing Effectiveness." His book "Winning the Service Game" (Harvard Business School Press) has been published in several languages. His service articles have appeared in Academy of Management Review, Journal of Applied Psychology, Sloan Management Review, Organizational Science, and Organizational Dynamics.

Richard B. Chase is Justin Dart Professor of Operations Management at the Marshall School of Business, University of Southern California. He is co-author with N. Aquilano and R. Jacobs of "Operations Management for Competitive Advantage," ninth edition, and Fundamentals of Operations Management, third edition (with N. Aquilano, M. Davis). He is on the editorial boards of several journals including Production and Operations Management, Journal of Operations Management, International Journal of Service Management, Journal of Service Research, and Cornell Quarterly. His latest article is "Want to Perfect Your Company's Service? Use Behavioral Science" (with S. Dasu), Harvard Business Review, June 2001. Other recent articles include "The Strategic Levers of Yield Management," (with S. Kimes), Journal of Service Research, and "Linking the Customer Contact Model to Service Quality," Journal of Operations Management (with Andreas Soteriou), "The
Impact of Human Error on Delivering Service Quality (with DM. Stewart)," Production and Operations Management Journal.

Lori S. Cook is an Assistant Professor of Operations Management in the Department of Management at DePaul University. She received her $\mathrm{PhD}$ in industrial engineering from the University of Louisville. She has been involved in numerous consulting and educational activities for both service and manufacturing organizations. She previously held engineering positions with Kentucky Fried Chicken (KFC) Corporation and Armco Eastern Steel Division. Her current research interests include the employee impact on service quality improvement and service design. She is also the engaged in research to examine the strategic impact of quality management systems.

Sriram Dasu is an Associate Professor in the Department of Information and Operations Management, Marshall School of Business, University of Southern California. His primary research interests are in the area of global supply chain management and service operations. He has published several articles on these topics in leading journals such as Operations Research and Management Science. He is currently studying he design of service delivery systems that are tuned to the heuristics and biases employed by customers in evaluating social experiences.

Douglas M. Stewart is an Assistant Professor of Supply Chain Management at Michigan State University. He received his $\mathrm{PhD}$ from the University of Southern California where he also worked with the USC Center for Service Excellence. Professor Stewart's current research interests include performance metrics, the application of human error psychology to service quality improvement efforts as well as service design, service operations management and TQM. He has published in the Sloan Management Review, Harvard Business Manager, Journal of Production and Operations Management, Production and inventory Management, USC Business, and The Service Quality Handbook, on the topic of mistake-proofing services. In addition, he has co-authored a book entitled Mistake-Proofing, and lectured on the subject to both academics and business professionals.

David A. Tansik is an Associate Professor in the Department of Management and Policy in the Eller College of Business and Public Administration at the University of Arizona. $\mathrm{He}$ has a $\mathrm{PhD}$ from Northwestern University in organization theory, and has published in such journals as Public Administration Review, Academy of Management Journal, Academy of Management Review, Journal of Operations Research, Management Science, Decision Sciences, Journal of Technology Transfer, and the International Journal of Service Industry Management. He is on the editorial boards of International Journal of Service Industry Management and the Journal of Service Research. His work in services organizations focuses on the management of customer organization interfaces. Of interest here is the design of services organizations where customers may be an integral part of the service creation and delivery process, and the design of jobs for high customer-contact service workers. 